OTOLOGY IN ITS RELATION TO RHINOLOGY AND LARYNGOLOGY.*

CLARENCE JOHN BLAKE, M. D.

Professor of Otology, Harvard University. BOSTON.

The history of otology is that of the cumulatively accretive study of an organ of special sense having for its purpose the appreciation of two distinct modes of motion and, additionally, tactile functions in relation to the sensorium and reflexly in relation to other organs, which constitute it one of the most important watch towers of the human citadel.

Early in the investigations into the structure of the human body, the organ of hearing was a favorite resource of the anatomist. To it he turned as to a labyrinth of suggestions and the delicacy of adjustment of the mechanism of its sound transmitting apparatus was an interesting microcosm of the larger joints and more gross muscular adjustments of the trunk and limbs which he had already explored.

Judged by their printed records the human ear was a veritable attraction to the older anatomists and the accuracy with which its intricacies are described is equaled only by the vagueness of the conceptions as to the manner in which it performed its functions, and the attractiveness of its study would seem to have had its foundation both in the demonstrably consecutive arrangement of its delicately constructed parts, and in the mystery attending the question of their related uses. Much of this mystery still remains uncleared, new questions still arise as to the methods of intratympanic and cranial sound transmission, the physical question of the translation of sound waves, through fluids of different densities, in enclosed cavities, is still unsolved and the later demonstrations of the diffusion of the blood supply within the labyrinth are helping to explain the sequence of morbid conditions not heretofore understood.

\section{SCOPE OF OTOLOGY.}

Otology still presents a broad and alluring field for original research and clinical investigation. The slowly progressive changes in the middle ear, gradually inhibiting its function of sound transmission, the reflex relationships between the middle ear and labyrinth and other organs, the bearing which the general systemic condition has on the blood supply and the transmission and perceptive functions of this complex organ, the elucidative information which may be obtained from it in eliminative diagnosis, emphasizing the statement that the ear is a small window through which it is possible to get a broad view if one only gets close enough to it, all point to otology as a distinctive department of laboratory and clinical research sufficient in itself to command the study of a lifetime, and scientifically remunerative, both in itself and in its centralizing relationship to other branches of investigation.

\section{O'TOLOGY AND RHINOLOGY.}

Viewed from the scientific standpoint alone the relationship of otology to rhinology is mainly that which concerns the middle ear and has to do with questions of blood supply, of variations in intratympanic atmospheric pressure and in the consideration of the nasopharynx as a reservoir of possibly, mechanically invasive microorganisms. In the early days of clinical otology the

- Read in the Section on Laryngology and Otology of the American Medical Association, at the Fifty-seventh Anzual Session, June, 1906. regions of the posterior nares and of the nasopharynx were practically unknown, or disregarded, fields. The part played by micro-organisms in the causation of diseases, surgically remediable, was yet to be discovered, the importance of the integrity of the nose and nasopharynz to the proper aëration of the tympanic cavity was unappreciated, and cases of persistent aural symptoms, dependent on the presence of obstructive growths in the naso-pharynx, sufficient to produce also the now well known facial symptoms, passed by on the streets and through the out-patient departments of the hospitals unnoticed.

Catlin, that intimate observer of the native American, whose gallery of portraits of Indian braves is one of the choice possessions of the Smithsonian Institution, marked the difference between the facial expressions of the Indians and the Caucasians and, in his trenchant book under the title "Keep Your Mouth Shut," not only limned the contrasts with his pencil but, with his pen, drew stringent inferential comparisons between the two races, the possessor and the invader of the native American soil, as to their inherent moral qualities, but with no thought of a physical cause. It was not until, almost simultaneously, Meyer in Copenhagen, Löwenberg in Paris, and Franklin Hooper and the writer, in this country, drew attention to the clinical bearing on respiration and aural function of the presence of the so-called adenoids, that an important practical binding step between otology and rhinology was established. This step led naturally to more intimate study and more reasonable regard of the boundaries within which these two departments could harmonize their efforts, a boundary line within which there is still large opportunity for both distinctive and collaborative research.

In following the history of any special branch of medical research and practice, it is necessary to recognize the fact that the story runs in two lines of distinct differentiation: the history of the specialty in the line of research shows it to be definite and consecutive, while the history of practice is marked by the variations incident to time and place and the limitations of fiduciary considerations. As a line of research otology has always had, and still presents, within itself, sufficient reason for its independent maintenance and for its representation as a department of education in our medical schools, but in the matter of practice its association with cognate specialties is influenced by considerations outside of the limits of true specialization.

A distinct line of research from its beginning, otology, bearing a definite relationship to general medicine but implying particular aptitude and entailing particular training and being, in its practical application, a limited field, fell into relationship first with another special branch of medicine and surgery requiring particular training for its study and tactile gifts for its application, and the practice of otology became linked with the practice of ophthalmology on a purely sumptuary basis without physiologic ground for the relationship.

\section{OTOLOGY AND OPHTHALMOLOGY.}

Ophthalmologic practice had already become well established when otology entered the practicing field and it was but natural that the younger of the two earliest specialties in medicine should come to be regarded as an addendum to the elder, especially as both require the same class of special training and much the same kind of individual aptitude in their practitioners.

Consequently, in the second stage of its special de- 
velopment we find ophthalmology and otology associated both in practice and in teaching and the dissociation is of so recent a date as to be still in progress. Up to thirty-five years ago the appointment of an ophthalmic surgeon to the Massachusetts Charitable Eye and Ear Infirmary carried with it the obligation to receive, and to treat, such cases of disease of the ear as might present themselves in the course of the service and it was not until 1870 that in the distinctive post of aural surgeon was established a step in advance, which was shortly coupled with another, the formal recognition, on the part of the board of managers, of medical teaching as one of the vital functions of an institution for the dispensation of medical charity, and it is only within a year that the joint chair of ophthalmology and otology in one of our larger schools, the University of Michigan, has been divided, and two separate professorships established.

\section{CONCLUSION.}

The relationship between otology and laryngology has as little a physiologic foundation as that above mentioned, but between otology and rhinology there is both a physiologic and a practical basis for collaboration, which is however especially concerned with that portion of the organ of hearing devoted to sound transmission and finds its own limitation of relationship in this respect. The service rendered to otology by the later advances in rhinology while computable as great, still remains to be definitely determined, because the end has not yet been reached, and is to be attained only by carefully compared coöperative observation, and it is the necessity for this which makes the true relationship of these specialties. To attain the best results it is important that the two should not be too much merged, since each offers a broad field for study, in its particular region, which it is advisable to conserve, and each has individual points of departure along lines of its own association. To study rhinology from the otologic standpoint alone is greatly to circumscribe rhinology, while to study otology from the rhinologic standpoint only is to leave out of consideration much that is of importance to an organ of special sense which has varied relationships with the functions of other organs and with the well being of the human economy as a whole.

The association of otology with ophthalmology was one of economic origin and without scientific reason, the association with laryngology has always been one of uncertain tenure, and it is the association with rhinology alone that has any substantial ground for persistence, and that to a limited extent, for, inevitably, as rhinology grows, and there could be no better evidence of growth than the number of valuable contributions, both in original research and in clinical observation which mark the program of this and of similar meetings, it will become more and more a distinctive field, capable of commanding the individual devotion of the scientific investigator and earnest practitioners, as otology has done from its beginning.

\section{DISCUSSION.}

Dr. R. G. Shambaugh, Chicago, said that the very intimate relations which exist between what have sometimes been considcred two separate specialties-rhinology and otology-can not be too often or too forcibly emphasized. He thinks that otologists are willing to admit that the most important chapter in recent years, aside from aural surgery, has been added to our knowledge of otology through the study of rhinology.

He fears that some as yet have a very poor appreciation of just what this relationship between rhinology and otology means, and so long as the subject is still of a more or less indefinite nature, some perhaps are inclined to think that relationships are seen which do not exist. Every rhinologist has had the experience of examining patients who had pre viously consulted other physicians who had advised operations on the nose, perhaps on the throat, when there was no reason whatever for operative interference. It seems to be not an uncommon thing to advise a patient suffering from chronic catarrh of the middle ear to have any little anatomic variation in the nasal chamber such, for example, as a small crest on the septum, removed for the purpose of benefiting the ear. All sorts of impossible imaginary relations are believed by some to exist between nose and ear trouble. Important relations do exist between middle-ear disease and conditions in the nose and throat, but it does not follow that every case of chronic middle-ear catarrh requires an operation on the nose or throat. The most important relation between the nose and throat and ear trouble is that found when the pharyngeal tonsil is enlarged. Most of the patients in middle life who present themselves for treatment of chronic middle-ear catarrh could have been greatly benefited had the proper attention been given to the adenoids in early life. When these patients are seen in middle life, however, the period when the ear disease is being influenced by the condition in the nose or throat has usually long since passed, and the only interference in the nose or throat that is justifiable is such as may be indicated to relieve local trouble in these parts anc no effect on the ear trouble from such treatment can be expected.

Dr. Otтo T. Freer, Chicago, referred to Dr. Blake's statement concerning the number of specialties which may be associated by a man wishing to keep his work up to the highest standard of excellence and progress. He agreed with $\mathrm{Dr}$. Blake that this number is diminishing and will in time be limited to one. Twenty years ago the eye, ear, nose and throat physician could keep up his knowledge, technic and instrumentarium, in all his fields. It is impossible for him to do so to-day, when each branch includes a literature so vast and manipulations so difficult that inly constant diligence makes it possible to keep up with progress. Inevitably, therefore, the man who assumes so many specialties will slight one or more of them. In this way many eye, ear, nose and throat specialists are to-day making the noble sciences of laryngology and rhinology mere appendages to eye and ear work, timidly and ineffectively entering into the treatment of the diseases of the nose and throat. While in smaller towns it will always be necessary to practice several specialties, in a few years he who does so in the larger cities will be looked on as representing a commercial rather than a scientific class of workers.

\section{MULTIPLE NEUROMATA OF THE SKIN.*}

WILLIAM EDGAR DARNALL, A.M., M.D. ATLANTIC CITY, N. J.

This subject is one that is noticed in very few textbooks of medicine and very scant attention is given to it in those that do refer to it. From the quotations given below it may be seen that the affection is not common, even in the broadest application of the term. I have collected three cases, reported herewith.

This form of tumor presents itself in the form of multiple hard spindle-shaped masses, varying in size from that of a small pea to that of a walnut, and distributed along the course of a single nerve, or of all the nerves of an extremity, or even the whole body. It originates from the connective tissue of the nerve sheaths and usually contains within its substance a certain number of nerve fibers included by the tumor in the course of its development.

"Painful neuroma of the skin is an exceedingly rare form of the affection, only two cases in which the skin was primarily

* Read in the Section on Diseases of Children of the American Medical Association at the Fifty-seventh Annual Sesstion, June, 1906 . 